\title{
DESIGN AND SIMULATION OF TORSION BAR(ARB) FOR FSAE USING MATLAB
}

\author{
Parimala Pavan Jonnada \\ B.Tech Mechanical Engineering, School of \\ Mechanical Engineering, Vellore Institute of \\ Technology, Chennai, India - 600127
}

\author{
Dr. Sreekanth Dondapati \\ Head of Department, School of Mechanical \\ Engineering, Vellore Institute of Technology, \\ Chennai, India - 600127
}

\begin{abstract}
Formula SAE is a student design competition organized by SAE International (previously known as the Society of Automotive Engineers, SAE). The concept behind Formula SAE is that a fictional manufacturing company has contracted a student design team to develop a small Formulastyle race car. The prototype race car is to be evaluated for its potential as a production item. Each student team designs, builds and tests a prototype based on a series of rules, whose purpose is both ensuring on-track safety and promoting clever problem solving. An anti-roll bar is a part of automobile suspensions that helps reduce the body roll of a vehicle during fast cornering or over road irregularities. It connects opposite wheels together through short lever arms linked by a torsion spring. A sway bar increases the suspension's roll stiffness-its resistance to roll in turns, independent of its spring rate in the vertical direction. In this research paper, calculation for the anti-roll bar mechanism will be simpler, and more accurate than hand calculations. Calculation was done using MATLAB and further analysis using FEA in ANSYS.
\end{abstract}

Keywords- Anti Roll Bar; FEA; MATLAB; Sway Bar; Torsion; FSAE

\section{INTRODUCTION}

An anti-sway or anti-roll bar is intended to force each side of the vehicle to lower, or rise, to similar heights, to reduce the roll of the vehicle on curves, sharp corners, or large bumps. With the bar removed, a vehicle's wheels can tilt away by much larger distances. Although there are many variations in design, a common function is to force the opposite wheel's shock absorber to the same level as the other wheel. For example, in a fast turn, a vehicle tends to drop closer onto the outer wheels, and the sway bar soon forces the opposite wheel to also get closer to the vehicle. As a result, the vehicle tends to "hug" the road closer in a fast turn, where all wheels are closer to the body. After the fast turn, then the downward pressure is reduced, and the paired wheels can return to their normal height against the vehicle, kept at similar levels by the connecting sway bar.

Because each pair of wheels is cross-connected by a bar, the combined operation causes all wheels to generally offset the separate tilting of the others and the vehicle tends to remain level against the general slope of the terrain.

Anti-roll bars provide two main functions. The first function is the reduction of body lean. The reduction of body lean is dependent on the total roll stiffness of the vehicle. Increasing the total roll stiffness of a vehicle does not change the steady state total load transfer from the inside wheels to the outside wheels, it only reduces body lean. The total lateral load transfer is determined by the CG height and track width.

The other function of anti-roll bars is to tune the handling balance of a car. Understeer or oversteer behavior can be tuned out by changing the proportion of the total roll stiffness that comes from the front and rear axles. Increasing the proportion of roll stiffness at the front increases the proportion of the total load transfer that the front axle reacts to-and decreases the proportion that the rear axle reacts to. In general, this makes the outer front wheel run at a comparatively higher slip angle, and the outer rear wheel to run at a comparatively lower slip angle, which is an understeer effect. Increasing the proportion of roll stiffness at the rear axle has the opposite effect and decreases understeer.

\section{CALCULATION}

3 cases have been considered, with the material as our variable. Result will be considered based on the torsion bar which has the least torsional shear stress values when compared with the max. tortional shear stress. The main objective is to calculate the diameter of the torsion bar (hollow), and to compare the theoretical shear stress calculated with the values of max. shear stress of the material, and with results from ANSYS simulations. 
To begin with, an assumption for the length and thickness of the 'pin-joint' has been taken (Ref. to Figure 1).

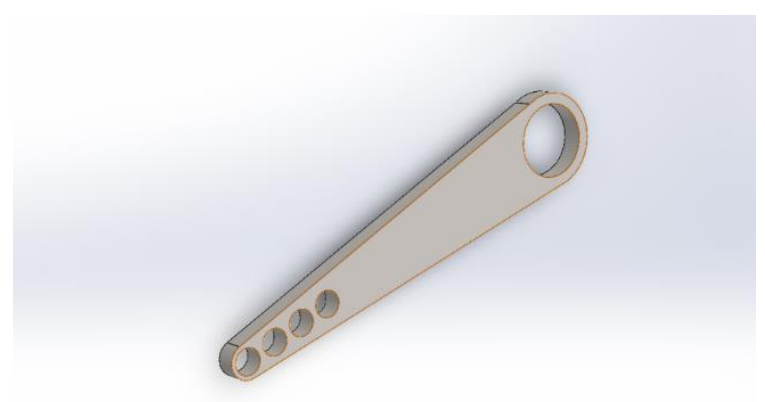

Figure 1 : Pin-Joint

At this point, the length of the torsional bar required, is from the kinematic diagram which is already designed. The forces which will act upon the bellcrank of the vehicle have to be calculated/retrieved, which will lead to the result of the torsion acting on the 'torsion bar' of the anti-roll bar mechanism. Using the thickness and length of the pin-joint, the angle is found at which the polar moment of inertia is acted upon. At this point, all the factors are available for calculating the polar moment of inertia acting on the torsion bar. From this value, calculation of the diameter of the tube is done. As a hollow tube is feasible as the torsion bar, this diameter will be considered as the outer diameter of the torsion bar. Following this, the inner diameter will be retrieved. Finally, the theoretical torsional shear stress of the tube can be retrieved. Also, design of torsion bar on DSS Solidworks and analyze for torsional shear on ANSYS, which will be the equivalent torsional shear. In order to utilize this torsion bar, both the torsional shear values must be less than the maximum torsional shear stress value of the material.

In our cases, the length of the torsion bar is $530.678 \mathrm{~mm}$. Thickness of pin-join is $5 \mathrm{~mm}$. Length of pin-joint is $92 \mathrm{~mm}$. Force exerted on bell crank is $872 \mathrm{~N}$. The Young's Modulus and Poisson's ratio varies, according to the material.

\section{CODE}

clc

clear all

syms pi J D T L G t 1 F R E v

$\mathrm{L}=$ input('Enter length of torsion $\operatorname{bar}(\mathrm{mm}):$ ')

t=input('Enter thickness of pin-joint(mm): ')

l=input('Enter length of pin-joint(mm): ')

$\mathrm{F}=$ input('Enter force exerted on bell $\operatorname{crank}(\mathrm{N}):$ ')
E=input('Enter Youngs Modulus (Modulus of

Elasticity) (GPa): ')

$\mathrm{v}=$ input('Enter Poissons Ratio: ')

$\mathrm{G}=(\mathrm{E} /(2 *(1+\mathrm{v})))$

$\mathrm{T}=\mathrm{F}^{*}(1 / 1000)$

$\mathrm{R}=\mathrm{t} / \mathrm{l}$

$\mathrm{O}=\operatorname{atan}(\mathrm{R})$

$\mathrm{J}=\left((\mathrm{T} * \mathrm{~L}) /\left(\mathrm{G}^{*} \mathrm{o}\right)\right)$

$\mathrm{pi}=3.1415$

$\mathrm{D}=((32 * \mathrm{~J}) / \mathrm{pi})^{\wedge} 0.25$

$\mathrm{D}=$ input('RoundD : ')

$\mathrm{d}=\left(\left(\mathrm{D}^{\wedge} 4\right)-((32 * \mathrm{~J}) / \mathrm{pi})\right)^{\wedge} 0.25$

$\mathrm{d}=\operatorname{input}\left(\operatorname{Round}(\mathrm{d}) \mathrm{:}^{\prime}\right)$

$\mathrm{t}=\left(\left(16^{*} \mathrm{~T}\right) /\left(\mathrm{pi}^{*}\left(\left(\mathrm{D}^{\wedge} 3\right)-\left(\mathrm{d}^{\wedge} 3\right)\right)\right)\right)^{*} 1000$

\subsubsection{Case (i) :}

Material $=$ AISI 4130 Steel $(E=200 \mathrm{GPa}, \mathrm{v}=0.3)$

Maximum torsional shear stress $=265 \mathrm{MPa}$

Enter length of torsion bar(mm): 530.78

$\mathrm{L}=530.7800$

Enter thickness of pin-joint(mm): 5

$\mathrm{t}=5$

Enter length of pin-joint(mm): 92

$1=92$

Enter force exerted on bell crank(N): 872

$\mathrm{F}=872$

Enter Youngs Modulus (Modulus of Elasticity) (GPa): 200

$E=200$

Enter Poissons Ratio: 0.3

$\mathrm{v}=0.3000$

$\mathrm{G}=76.9231$

$\mathrm{T}=80.2240$

$\mathrm{R}=0.0543$

$\mathrm{o}=0.0543$

$\mathrm{J}=1.0195 \mathrm{e}+04$

$\mathrm{pi}=3.1415$

$\mathrm{D}=17.9517$

Round D : 18

$\mathrm{D}=18$

$\mathrm{d}=5.7886$ 
Published Online December 2020 in IJEAST (http://www.ijeast.com)

Round(d): 6

$d=6$

$\mathrm{t}=72.7545$

As observed, the theoretical torsional shear stress is $72.75 \mathrm{MPa}$

ANSYS Simlutaion:

Mesh Quality $\rightarrow$ Smoothing $\rightarrow$ Fine. The only parameter altered

From above MatLAB output, Torque $(\mathrm{T})=80.224$

$\mathrm{Nm}$.

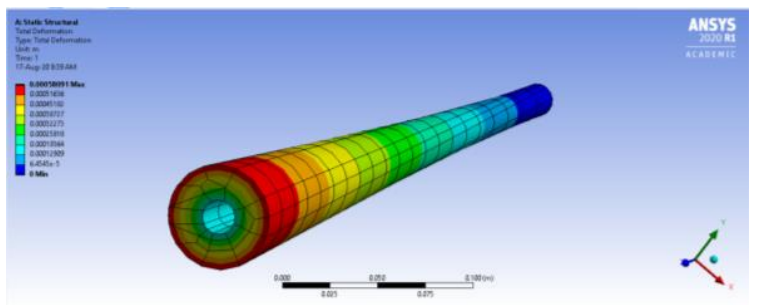

Total deformation

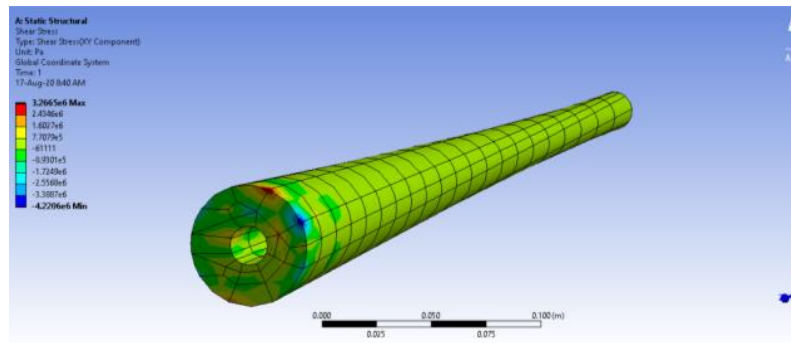

Shear stress

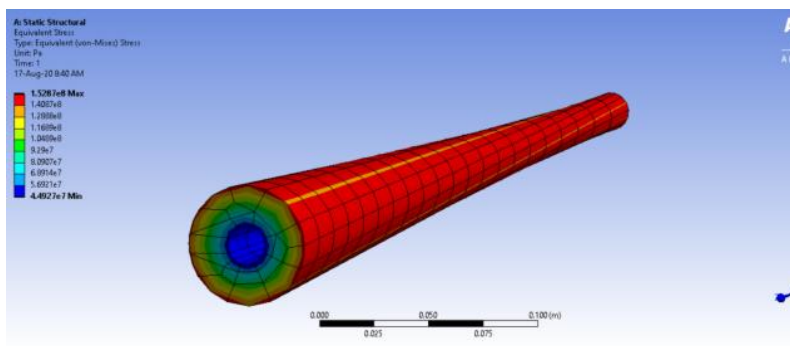

Equivalent stress

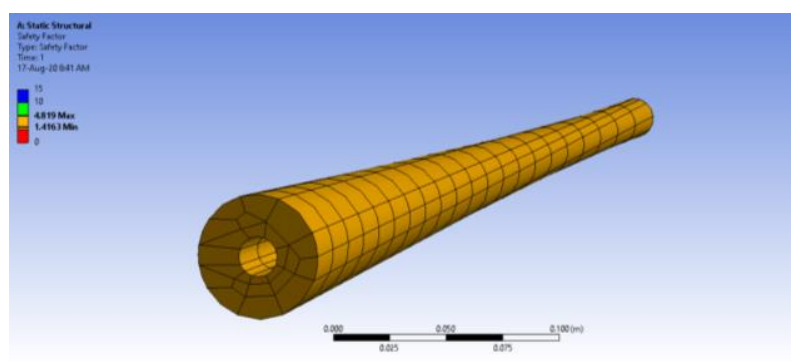

FOS
1.3.2 Case (ii):

Material: Ti-6Al-4V (E = $114 \mathrm{GPa}, \mathrm{v}=0.342)$

Maximum torsional shear stress $=575 \mathrm{MPa}$

Enter length of torsion bar(mm): 530.78

$\mathrm{L}=530.7800$

Enter thickness of pin-joint(mm): 5

$\mathrm{t}=5$

Enter length of pin-joint(mm): 92

$1=92$

Enter force exerted on bell $\operatorname{crank}(\mathrm{N}): 872$

$\mathrm{F}=872$

Enter Youngs Modulus (Modulus of Elasticity) $(\mathrm{GPa}): 114$

$\mathrm{E}=114$

Enter Poissons Ratio: 0.342

$\mathrm{v}=0.3420$

$\mathrm{G}=42.4739$

$\mathrm{T}=80.2240$

$\mathrm{R}=0.0543$

$\mathrm{o}=0.0543$

$\mathrm{J}=1.8465 \mathrm{e}+04$

$\mathrm{pi}=3.1415$

$\mathrm{D}=20.8252$

RoundD : 21

$\mathrm{D}=21$

$\mathrm{d}=8.9429$

Round(d): 9

$\mathrm{d}=9$

$\mathrm{t}=47.8891$

$>$

As observed, the theoretical torsional shear stress is $47.89 \mathrm{MPa}$

ANSYS Simulation:

Mesh Quality $\rightarrow$ Smoothing $\rightarrow$ Fine. The only parameter altered

From above MatLAB output, Torque $(\mathrm{T})=80.224$

$\mathrm{Nm}$. 


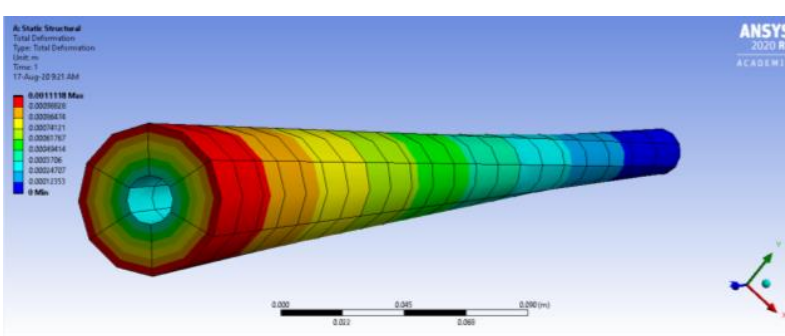

Total Deformation

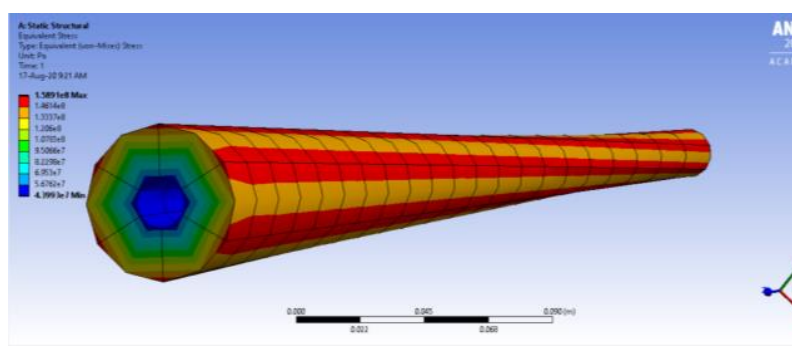

Equivalent Stress

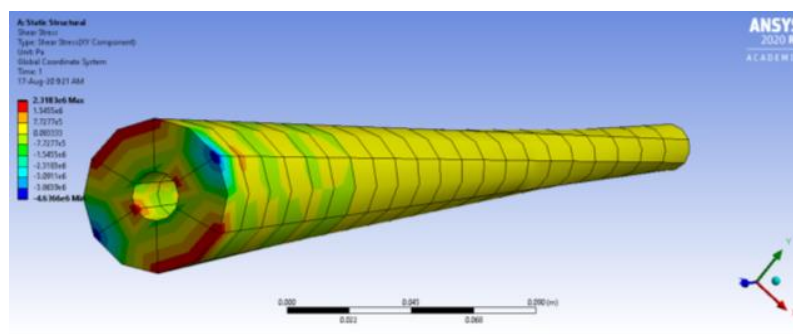

Shear Stress

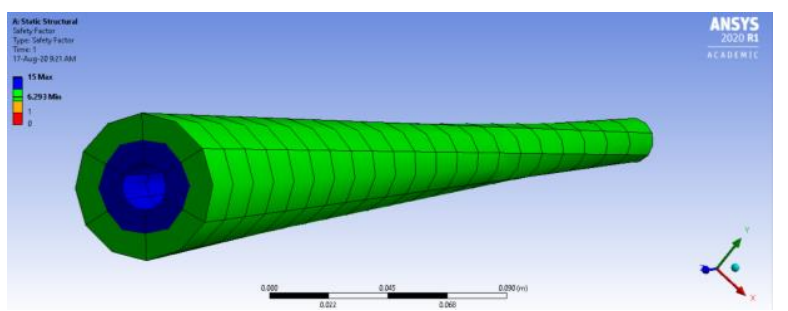

FOS
IV. RESULTS

\begin{tabular}{|l|l|l|}
\hline & AISI 4130 & Ti-6Al-4V \\
\hline $\begin{array}{l}\text { Theoretical } \\
\text { Torsional Shear } \\
\text { Stress }\end{array}$ & $72.75 \mathrm{MPa}$ & $47.88 \mathrm{MPa}$ \\
\hline $\begin{array}{l}\text { Total } \\
\text { Deformation }\end{array}$ & $0.588 \mathrm{~mm}$ & $1.11 \mathrm{~mm}$ \\
\hline Equivalent Stress & $152 \mathrm{MPa}$ & $158 \mathrm{MPa}$ \\
\hline Shear Stress & $3.226 \mathrm{MPa}$ & $2.31 \mathrm{MPa}$ \\
\hline FOS & $1.4-4.8$ & 6.293 \\
\hline
\end{tabular}

\section{CONCLUSION}

The function of the ARB is to withstand the torsional moment actuated on it, in order to transfer energy within the wheels, which balances the overall ride of the vehicle. From the above table, Ti-6Al-4V material is more feasible than AISI 4130, in manufacturing the ARB.

\section{REFERENCES}

1 https://www.sae.org/attend/studentevents/formula-sae-electric/about

2 M. Kurkhe Nikhil, Dheeraj Hari Despute[2018] Dynamic Analysis of anti roll bar

3 https://www.researchgate.net/post/What_char acterization_required_for_automotive_antiroll_bar_applications

4 http://asm.matweb.com/search/SpecificMateri al.asp?bassnum $=\mathrm{m} 4130 \mathrm{r}$

5 http://www.matweb.com/search/DataSheet.as px?MatGUID=e1ccebe90cf94502b35c2a4745 f63593\&ckck=1

6 https://www.azom.com/article.aspx?ArticleID $=1547$

7 P.C.M. van den Bos[2010] Design of a Formula Student Race Car Spring-Damper System., 0576519 CST2010 